\title{
THE MOST ADVANCED SYSTEMS FOR PERFECT COIL PRODUCTION: THE LOOP LAYING HEAD (LLH) IS A COST- EFFECTIVE SOLUTION FOR THE LATEST GENERATION OF H3 HIGH-SPEED WIRE ROD MILLS*
}

Andrea Taurino
Massimo Vasi $^{1}$
Antonello Mestroni $^{1}$
Andrea De Luca
An complete name $^{5}$
$r^{5}$ 's complete name
r's complete name $^{6}$

\begin{abstract}
Innovation means implementing a new product or a product that has undergone significant improvement over time, in terms of method, form and performance. Innovation encompasses all the scientific, technological, organizational, financial and commercial steps that need to be taken to put it into operation. Innovation combined with research and development makes it possible to perfect the product with consistency over time. Taking inspiration from the bases developed by the Austrian economist Joseph A. Schumpeter back in 1911, Danieli came up with the concept of "Innovaction" - a combination of Innovation and Action, to refer to the development and advancement of various products for the steelmaking industry, including the loop laying head for wire rod.

Keywords: Oil film bearing; Loop laying head; H3; Turbo loop laying head; Pipeless rotor; Twin pipe rotor.
\end{abstract}




\section{THE ORIGIN OF THE “HEAD”}

Everything has a beginning and then evolves. In this article we have an extraordinary story to relate that changed the way in which steel and its by-products are processed, with particular attention to the production of wire rod coils, which over the years has been consistently evolving with significant increases in production speed (from $30 \mathrm{~m} / \mathrm{s}$ at the beginning of the $70 \mathrm{~s}$ to $130 \mathrm{~m} / \mathrm{s}$ today), and in the range of steels produced over more than forty years.

Danieli - being focused on technical innovation for plants, processes and technologies - over the years has developed a wire rod mill technology, encompassing all the aspects from rolling to coil forming through to the transformation process.

By way of our research and development we examined each of these processes in the minutest detail. The first steps occurred at the beginning of the 1970s with the introduction of Edenborn coilers. These were top-fed machines mounted on a frame, consisting of a funnel/bell with a rotating pipe inside it and a rotating plate underneath it for optimum coil forming. To remove the coil, the machine was fitted with a lateral hydraulic pusher, which transferred the coil to a shutter conveyor. Then, the coil was taken to the tying and storage areas. Persistent market demand for ever larger and heavier coils made it necessary to develop the Edenborn coiler further, so that it could process coils weighing more than $300 \mathrm{~kg}$ at speeds greater than $30 \mathrm{~m} / \mathrm{s}$. The first coil stability problems arose with the $700-\mathrm{kg}$ coils, since they were heavier than the ones previously produced using other methods. Consequently, the coil had to be contained both during forming and while it was being transported on the conveyor. As a partial remedy to this problem, pins were added to the forming system, but once the coil was transferred to the conveyor, it was free to move around, thereby compromising its stability.

This made it necessary to install a different type of conveyor at the exit of the Edenborn coiler; the new conveyor was equipped with rollers and had a dual function, namely:

- to provide a controlled heat treatment on the entire wire rod coil, resulting in a final product with uniform, optimum mechanical properties;

- to collect the loops and form a well-shaped, compact coil weighing more than the required $700 \mathrm{~kg}$, in order to improve material yield and make the plant itself more efficient.

That is how the first controlled cooling conveyor for wire rod came to be. It has undergone continuous improvements over the years through the application of progressively advanced technologies.

Markets and steelmakers became more demanding and competitive, and consequently this affected machine manufacturers, who were required to supply increasingly innovative technologies.

The first plants to use this technology at the beginning of the 70 s were Sudacier in France, Lechstahlwerke in Germany and others in South America and the Far East.

\section{THE FIRST-EVER LOOP LAYING HEAD IN OPERATION: 1975}

Given that market demand was veering toward higher rolling speeds, heavier coils, increased wire rod diameters, better shape, etc., coil forming using the Edenborn method was no longer efficient. Switching from vertical to horizontal coil forming had practically become a reality, especially since the new layout configuration enabled all heat treatments to be performed in line. This also resulted in a better coil shape. One of the first new loop laying facilities was installed at ALFA Acciai in Brescia; these 
machines ran uninterruptedly for 30 years before being replaced by more modern ones. They were designed with rolling bearings and for years they were market leaders, measuring themselves against similar machines developed by competitors. Then, new process technologies were developed and patented to reduce the vibrations caused by the increased finishing speed and wear, with design and materials optimized to reduce maintenance.

\section{THE EVOLUTION OF OUR FIRST GENERATION}

Market-driven changes in production programs were responsible for the next revolutionary development in the loop forming system, at the end of the 1990s. Because of exponential speed increases $(110 \mathrm{~m} / \mathrm{s}$ and more) in industrial operation and significant wear of the forming pipes, process developers turned their attention to the pipe path, which then was completely reformulated and enhanced mathematically through the use of cutting-edge computers and simulation software. Thanks to research on this new path by the Danieli Research Center, the lifetime of the former generations of pipes (500 tons of $5.5 \mathrm{~mm}$ rounds at $100 \mathrm{~m} / \mathrm{s}$ in 1995) saw a significant increase (with a production of more than 5,000 tons), thus making it economical to produce wire rod at that speed. The new path - referred to as Second Generation was tested for the first time on the loop laying head installed at Acciaierie e Ferriere Caleotto in 1998. This immediately became the standard that Danieli applied to that machine. But, the high rolling speed forced technicians to deal with another technological constraint, in the form of vibrations, it was possible to study, design and manufacture the Third Generation Laying head on an industrial scale.

From 1975 to 2002 Danieli supplied more than 108 Laying heads worldwide.

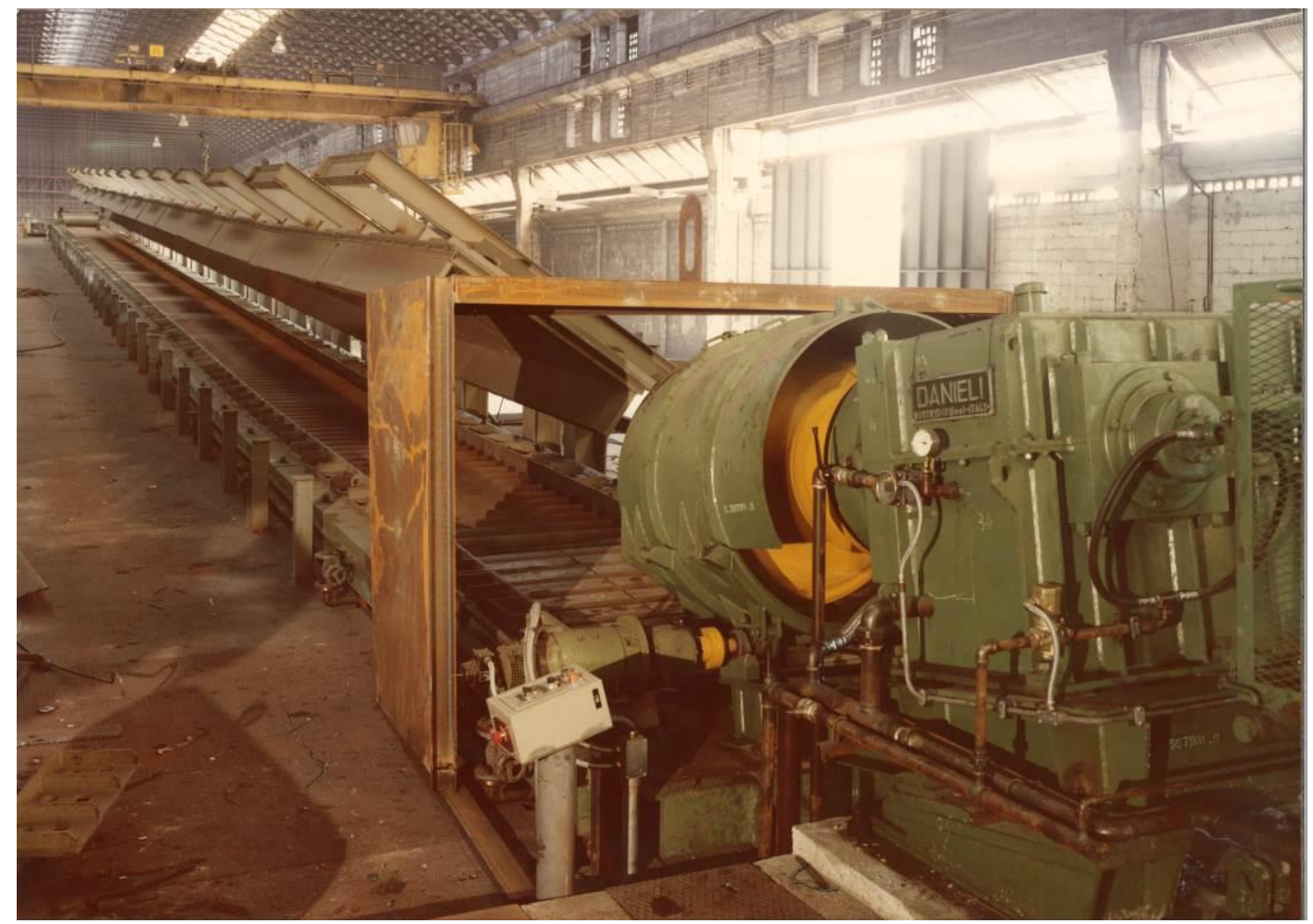

Figure 1. One of the first Loop Laying Heads in operation at ALFA Acciai - Brescia - Italy - 1975 


\section{THIRD GENERATION - THE “QUEEN"- OIL-FILM BEARING, PATENTED LOOP LAYING HEAD (2003)}

The need to extend the lifetime of the rotor support bearings, because of the high number of revolutions and the vibrations that were being generated, led us to look for and use another kind of bearing.

We eventually opted for oil-film bearings, a technology supported by our long experience in Cantilever stands and Wire Rod Blocks.

The first tests done on these bearings in 2002 showed that they could withstand a high number of revolutions, or high rolling speeds, with practically no vibrations, thus proving that an oil film is an excellent shock absorber.

The OFB laying head features a unique patented design, which uses "oil-film bearings" for rotor support (instead of traditional roller bearings). This provides absolute stability during operation, lower wear, and extended life for the laying pipe, as well as minimized maintenance.

Its advanced design ensures an optimal response even in highly unbalanced conditions, and vibration-free operation at full speed.

This Third Generation with the oil-film bearing, was fitted with all the improvements and refinements necessary to operate in the new working conditions:

- $150 \mathrm{~m} / \mathrm{s}$ in industrial operation and $170 \mathrm{~m} / \mathrm{s}$ in no-load conditions

- vibrations reduced to a minimum (kept below $2 \mathrm{~mm} / \mathrm{s}$ )

- 3D modeling to develop the new pipe shape needed to optimize the coil path

- research and application of wear-resistant materials

- use of a "smart" pinch roll (Active Pinch Roll) to handle the head and tail of the rolled stock

- use of advanced automation systems designed to properly center and lay the loops on the conveyor.

The first customer to use the third series LLH was SN Longos in Portugal, in the first months of 2003. This customer, within the framework of its wire rod mill revamping project, wanted to be the first to install two laying heads with oil-film bearings, because they were convinced that this was a reliable machine with potential. The two machines were started up quickly, primarily because working speeds of over $100 \mathrm{~m} / \mathrm{s}$ were also reached quickly, only a few weeks after the machines were installed.

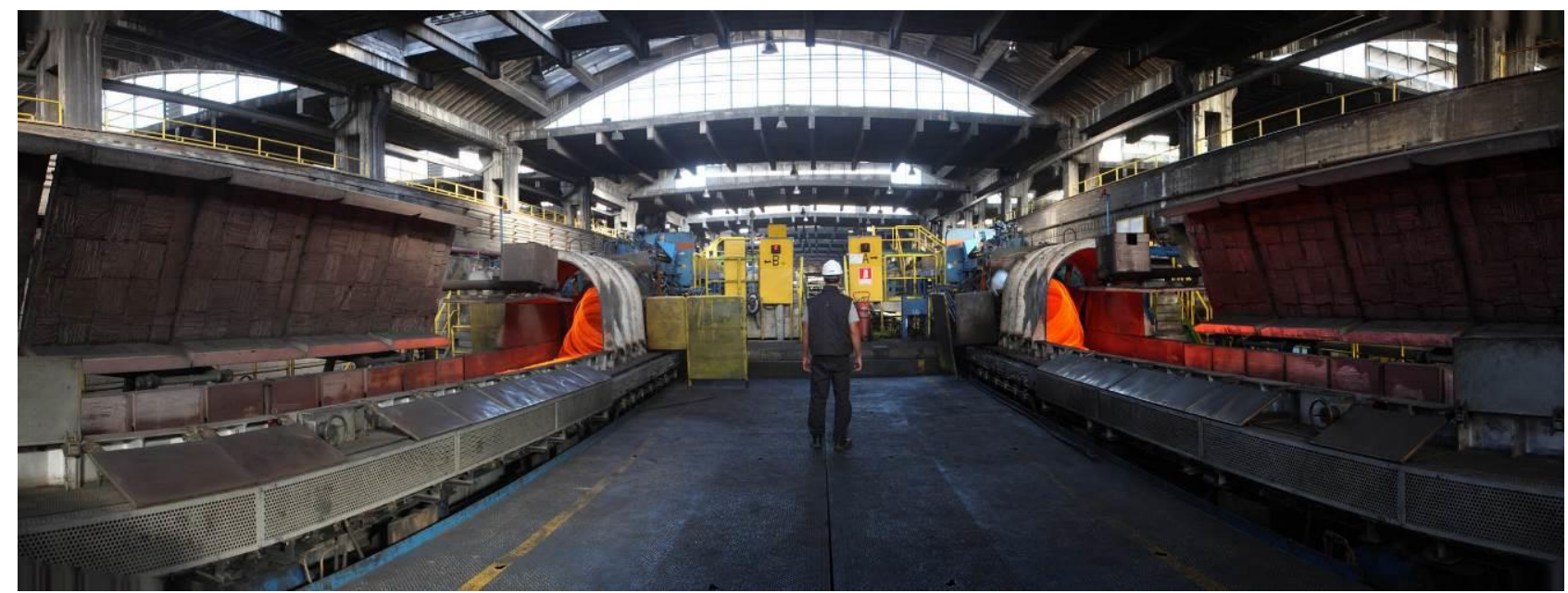

Figure 2. The latest generation OFB-LLH in operation at SN Longos - Portugal 
Ten years have passed since then, during which time more than 70 loop laying heads with oil-film bearings have been installed and started up successfully all over the world. In terms of quality and performance, these machines produced increasingly impressive results until the advent of the Fourth and Fifth Generation machines.

\section{THIRD GENERATION EVOLUTION - “TWIN PIPE ROTOR” LAYING HEAD}

Today, the latest developments in loop laying technology ensure a superior coil pattern and an optimized laying pipe wear rate with absolute operating stability and vibrationfree operation at production speeds of up to150 m/s.

The traditional laying head concept has changed radically with the application of the following innovations.

This advanced design, researched using 3D kineto-dynamic simulation, provides operating stability and reduced wear at high finishing speeds. The laying pipe's progressively curved shape gives the wire rod an ideal path inside the pipe, where it is in constant contact with the inner wall along the entire pipe length, for even wear distribution (70\% increase in pipe life).

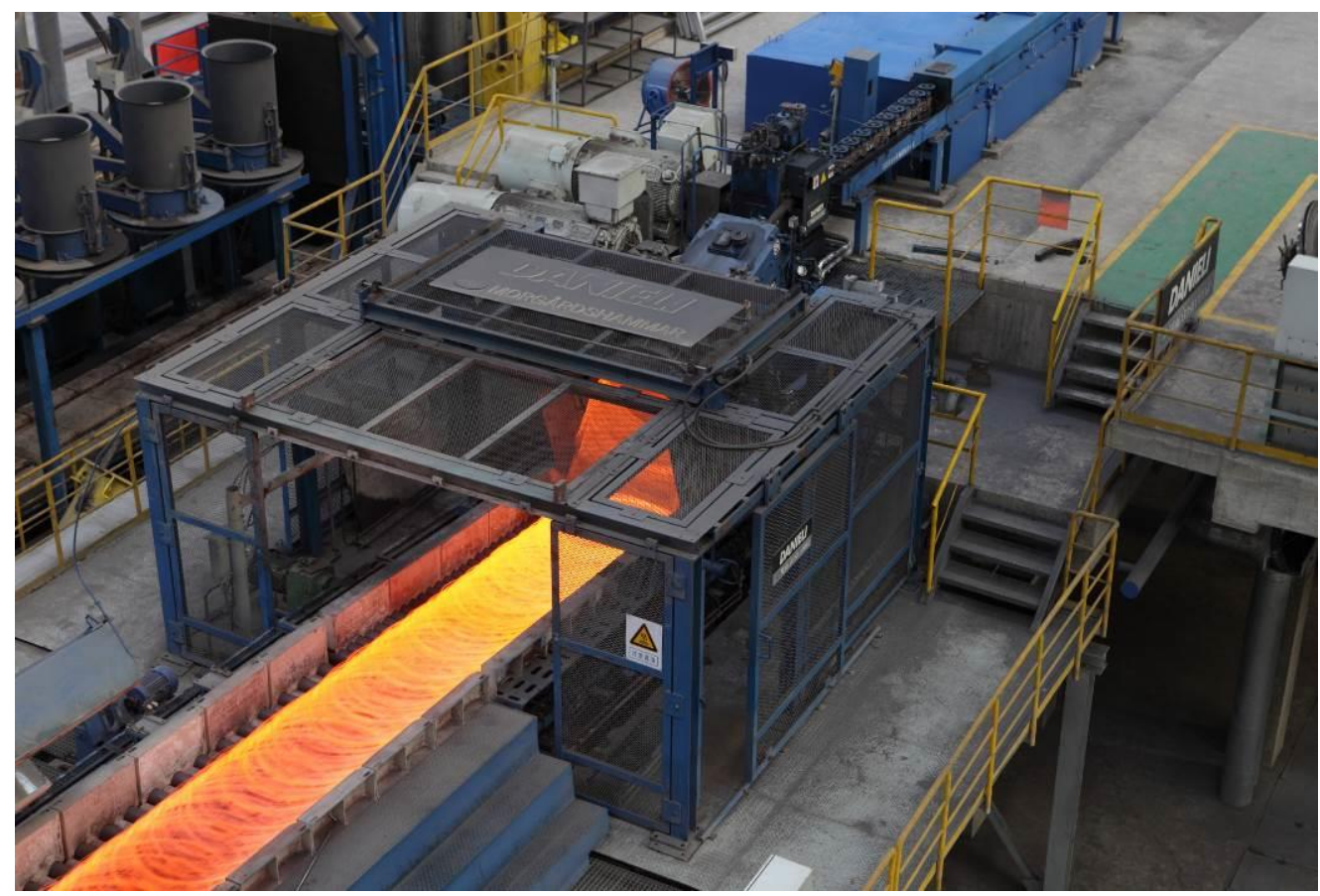

Figure 3. The latest generation LLH in operation at $\mathrm{H}^{3}$ High-speed wire rod mill in Tianjin MGZY I\&S P.R. of China

In order to fulfill our customers' requirements to increase the service life of the pipe and reduce the downtime for the rotor change, Danieli designed and put into operation a new "Twin Pipe Rotor", as an alternative to the traditional single-pipe rotor.

The results were better than expected, providing the mill operator with immediate benefits in terms of service life, coil pattern, surface quality, and head and tail formation.

- Long production campaign

- Up to 80,000 t before changing the rotor pipes

- Outstanding performances with small-size product mix (based on $>60 \%$ of small sizes from 5 to $12 \mathrm{~mm}$ )

- Internal pipe diameter optimized for small products 
- Excellent performances with lower pipe wear

- Pipes made of duplex stainless steel for long pipe life, even for alloyed steel grades

- Perfect head and tail pattern

- "ZERO" operators needed on the roller conveyor

- Special head/tail device avoids the need for human intervention on the roller conveyor/reforming pit

- Vibration-free during rolling (less than $1.5 \mathrm{~mm} / \mathrm{s}$ at $120 \mathrm{~m} / \mathrm{s}$ ) thanks to patented "oilfilm bearings"

- Low pipe wear thanks to optimized pipe shape and material (5-6 times longer life than conventional laying heads)

- Optimal formation of the last ring and head positioning in synchronization with the high-speed shear

- Special Danieli design for processing of large sizes (up to $27 \mathrm{~mm}$ ).
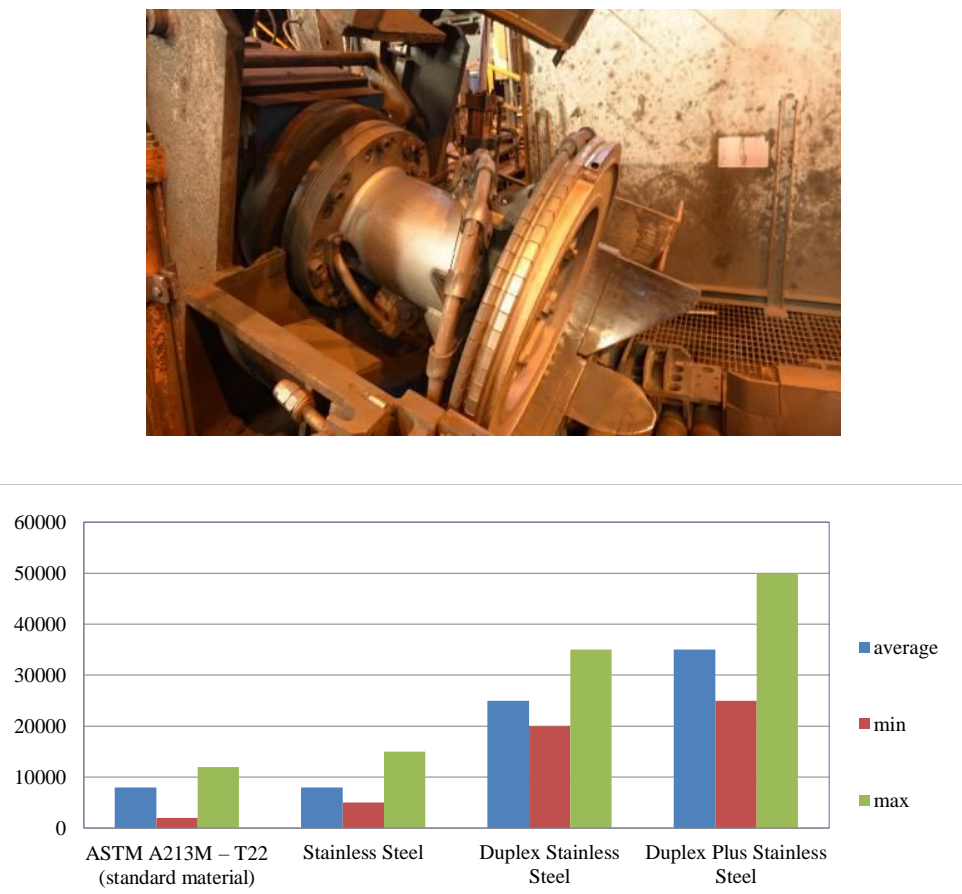

Figure 4 and 5. LLHPlus 2-pipe rotor installed at Ferriere Nord - Italy and Pipe lifetime comparison diagram

\section{FOURTH GENERATION - TLH-TURBO LOOP LAYING HEAD (PATENT PENDING)}

With the Third Generation laying head/rotors we achieved an optimized design that performs at very high speeds $(170 \mathrm{~m} / \mathrm{s}$ design speed and $150 \mathrm{~m} / \mathrm{s}$ in constant operation) with very few vibrations (less than $2 \mathrm{~mm} / \mathrm{s}$ at a speed of $120 \mathrm{~m} / \mathrm{s}$ ).

This proves that thanks to the use of calculations and 3-D design of the machines, the loop laying heads can reach unparalleled performances and first-rate finished product quality, with very low wear of the loop laying pipes and reduced need for spares (i.e., oil-film bearings .... no need for anti-friction bearings).

Notwithstanding our Third Generation achievements, Danieli researchers further developed, innovated and created an additional laying head generation. 
The Turboloop Laying Head, featuring a "Pipeless Rotor", offers numerous advantages for operators to produce mainly small diameters from 4.5 to $8 \mathrm{~mm}$ dia, which can be summed up as follows:

- Endless life for the rotor

- 1 rotor per year corresponding to the use 60 pipes...meaning reduced maintenance and downtimes

- It ensures repetitive loop formation with steady, regular laying on the Controlled Cooling Conveyor

- Reduced noise level from $110 \mathrm{dBA}$ to $86 \mathrm{dBA}$

- Diminished vibrations due to imbalance and axial-symmetrical wear as well as predictable and controllable wear, with no cobbles due to unexpected pipe wear.
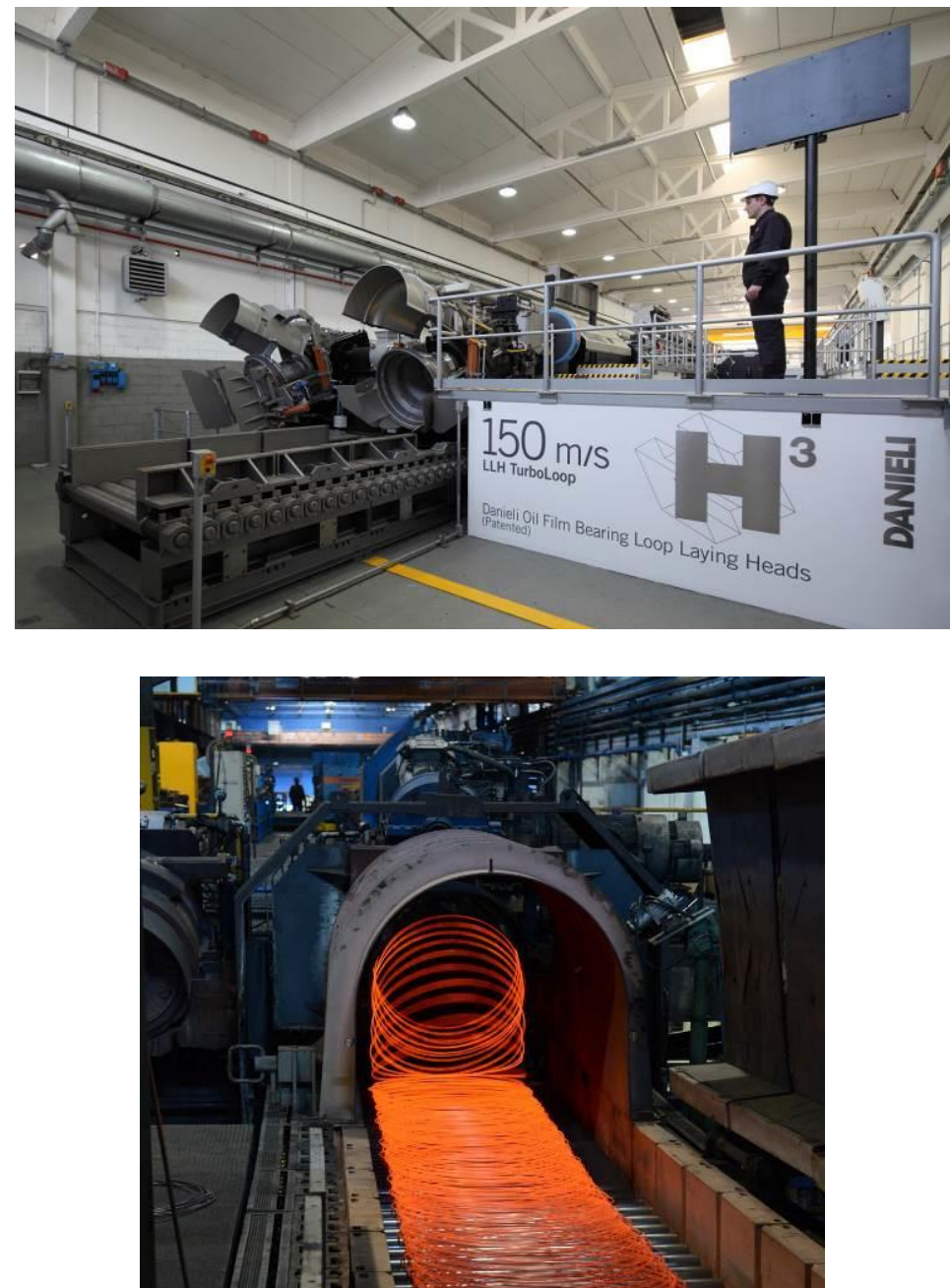

Figure 6 and 7 : Danieli $\mathrm{H}^{3}$ show room and TurboLLH in operation at Ori Martin - Italy

This innovative technology is applied to all new Danieli laying heads, and can be applied easily to upgrade existing units.

The machine's special design coupled with an advanced automation/control system enables regular formation and laying of wire rod tail loops onto the roller conveyor in a perfectly round shape. This means it is no longer necessary to remove the deformed wire rod tail loops from the roller conveyor manually, making this operation much safer. 


\section{DANIELI AUTOMATION FOR LLH}

The most challenging targets for the automation and drives system controlling the laying head are the formation of a perfect coil shape and the positioning of the head front end on the cooling conveyor.

For a good coil shape, the laying head rotation speed should follow precisely and with high dynamics the real speed of the material. Thanks to the introduction of proper automation algorithms the loop size is now perfect, even at bar head and tail.

In detail, for large sizes, speed wobbling is used to reduce the end size of the coil while at the tail a synchronized speed-up cycle of TMB, Pinch Roll and laying head is applied to push the material out of the pipe. This also promotes a regular diameter on the last loop. The use of full regenerative drive and proper main motor sizing is mandatory to perform such demanding speed cycles.

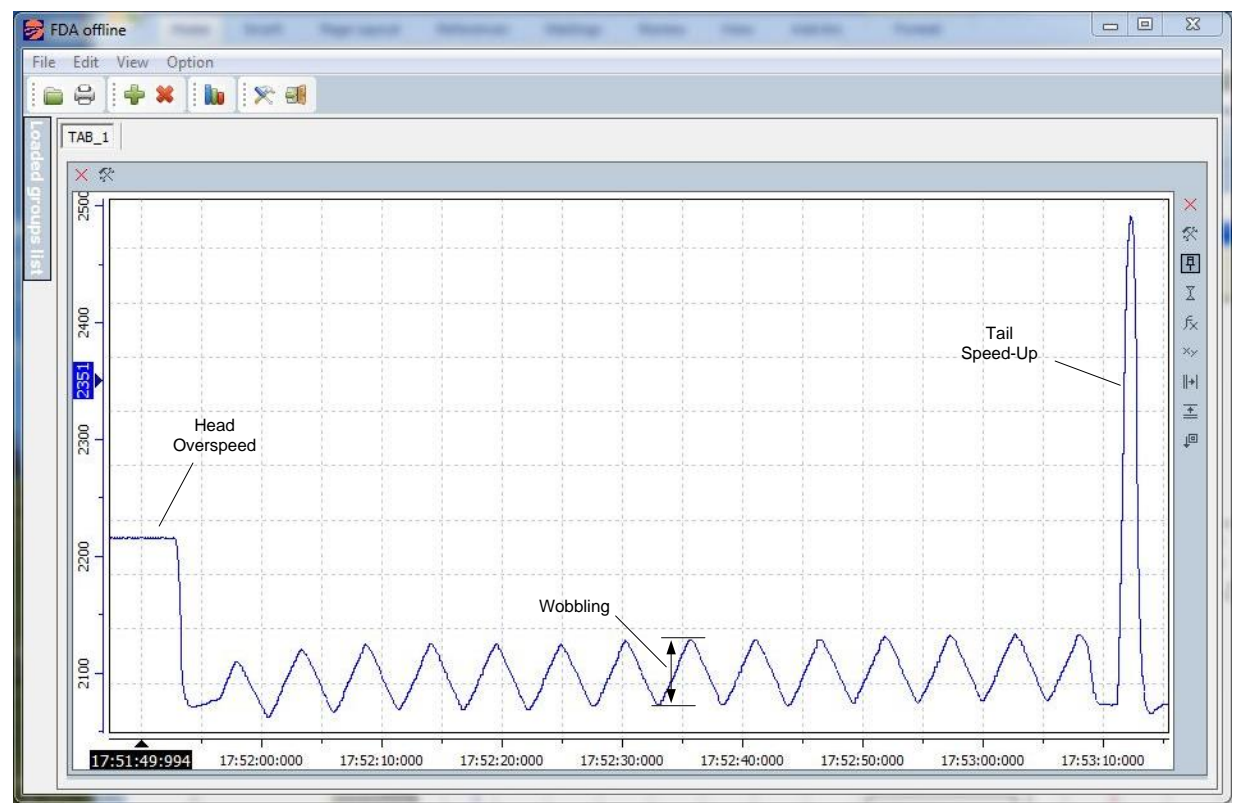

Figure 8: Laying head real speed recording at $\varnothing 18 \mathrm{~mm}$ rebar production

Support for the perfect loop formation comes from the introduction of the active pinch roll that achieves reliable and precise real rod speed measurement. Then, the measured speed is used to correct the laying head set speed. The correction is useful for high speed/small size rods at tail incoming in wire rod lines with TMB and in those connected to two strands rolling mills. 


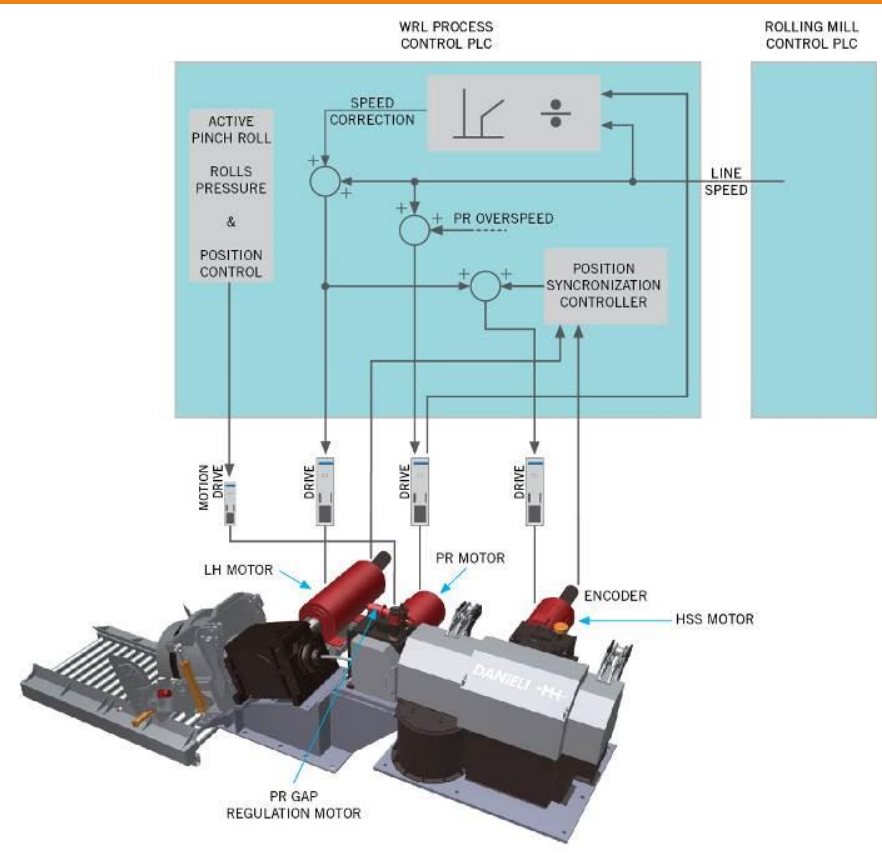

Figure 9: Line speed correction and front-end positioning control diagram (principle)

Exceptional precision for head front end positioning on the cooling conveyor is now possible with the introduction of the high-speed shear upstream the laying head. At material head incoming, the rotor of the high-speed shear is maintained in constant phase synchronism with the laying head rotor. For each turn of the laying head, the high-speed shear makes exactly two turns and when it performs the head cut the position of the laying head is exactly the one expected. The result is that the error in the positioning of the front end of the rod is less than $20 \mathrm{degr}$ at $120 \mathrm{~m} / \mathrm{s}$ rolling speed.

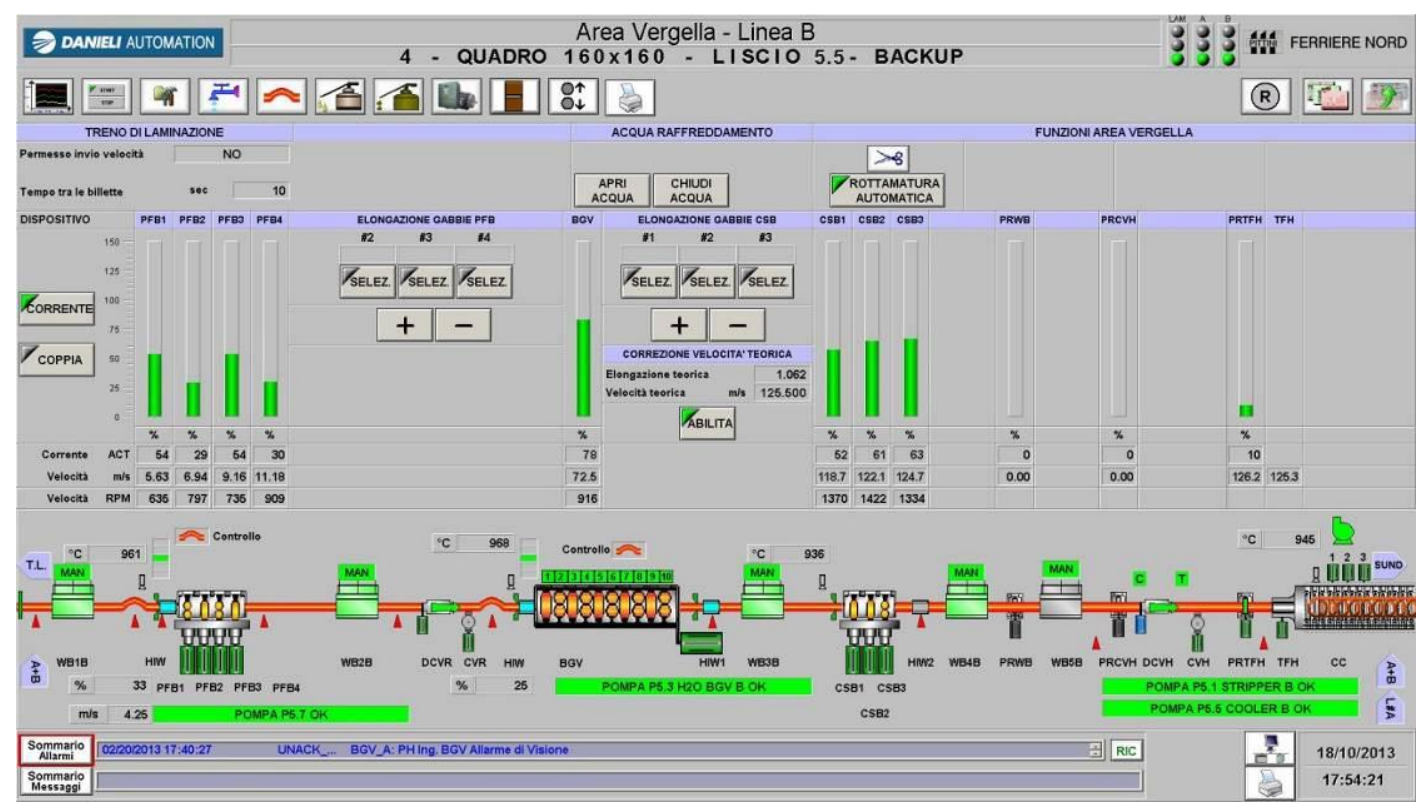

Figure 10: Ferriere Nord wire rod line supervision system with the world speed record of $126.2 \mathrm{~m} / \mathrm{s}$

\section{CONCLUSIONS}

As set out in this article, it took years of research, continuous improvement and teamwork to achieve the record speed of $126.2 \mathrm{~m} / \mathrm{s}$ like in Ferriere Nord plant. We 
relied on mutual trust and collaboration with our customers, as over the years the market has become more competitive, demanding increasingly tight machining tolerances, excellent quality of materials, and high-value and diversified products. As suppliers of processes and technologies, our task is to evaluate every possibility and combination in relation to the mechanics, hydraulics and electronics, but above all to the technological process. This is Innovation in action.

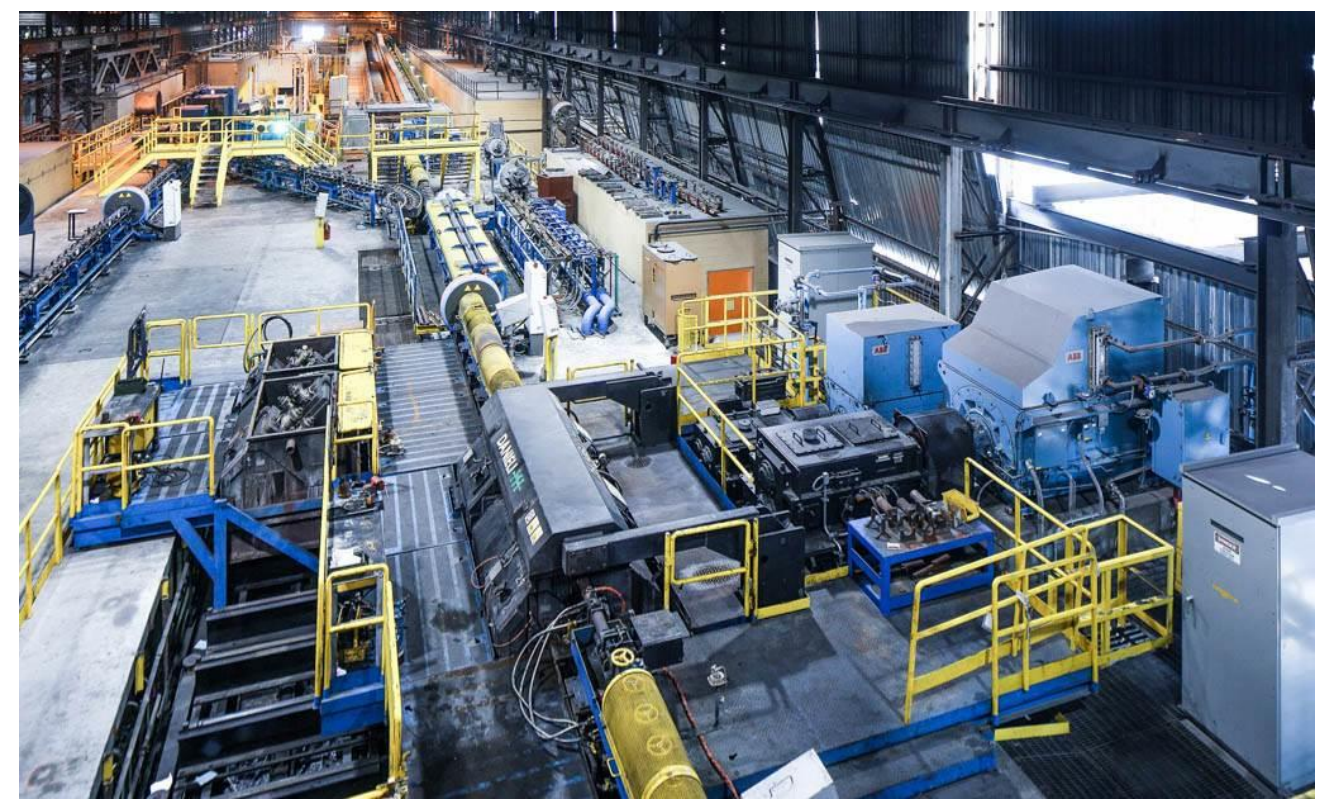

Figure 11: Nucor Darlington $\mathrm{H}^{3}$ wire rod line

\section{REFERENCES}

1 Another step toward the best quality wire rod with better productivity and higher efficiency, AISTech 2011 